\title{
Jobotifetime
}

\section{Emerging technologies at Towson University: The hat trick}

$\mathbf{W}$ hen members of the Towson University Albert S. Cook Library began their search for an emerging technologies librarian, they were expecting to select one technology-oriented, multifaceted individual. Months later, they found themselves revising their search to allow for the hiring of not one, not two, but three librarians who fit the bill.
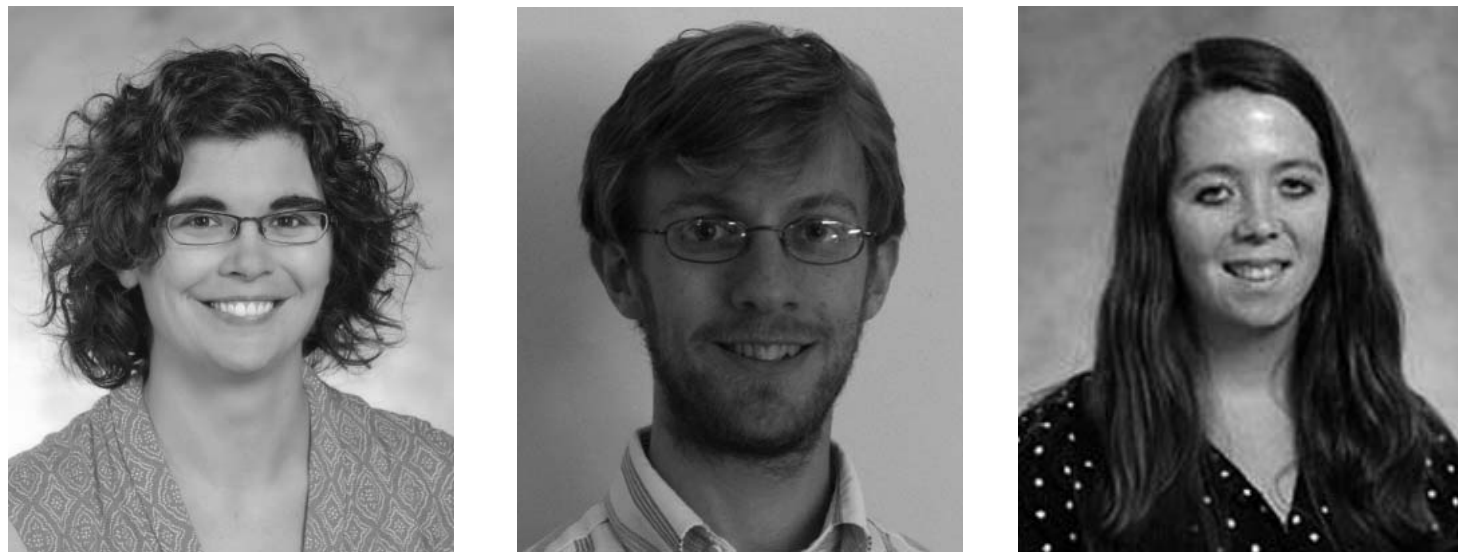

Carrie Bertling Disclafani, David Dahl, and Carissa Tomlinson, emerging technologies librarians at Towson University's Albert S. Cook Library.

Carrie Bertling Disclafani, David Dahl, and Carissa Tomlinson began as Emerging Technologies Librarians (ETLs) at Cook Library during summer 2008. All are recent LIS graduates (2007 and 2008) and are currently in their first post-LIS professional positions. Their job descriptions are newly created and were designed to bring fresh skills and ideas into the library.

However, Bertling Disclafani, Dahl, and Tomlinson don't want others to misunderstand their newfound jobs. "Being an ETL doesn't necessarily mean you are a programming computer geek," says Bertling Disclafani. The positions fall within the purview of reference and instruction, meaning that all three librarians must balance liaison activities, information literacy instruction, collection development, and reference service. Additionally, their investigations of emerging technologies are primarily intended to im- 
it's difficult to apply any kind of standardization across the board.

"We are not simply Web 2.0 librarians," says Tomlinson, with Bertling Disclafani adding, "I think our job is more about fearless exploration of new tools than extensive experience with any particular technology."

All three librarians indicate the importance of knowing when an emerging technology will benefit the library, filling an identifiable need rather than satisfying techno-lust.

"New technology for the sake of new technology doesn't make a whole lot of sense," says Tomlinson. "It's not always easy to match the right technology with the right need, and monitoring technological change can be time consuming."

According to Bertling Disclafani, "Technologies that are old news in one field may be at the prime for library emergence." The solution, says Dahl, is creativity-a necessity when working with emerging technologies.

"A lot of these (especially those of the Web 2.0 variety) have a certain function they're designed to perform, and it usually has nothing to do with libraries," says Dahl. "Creativity is often needed to make these viable tools for libraries."

\section{Never a typical workday}

A typical workday for the librarians would be hard to describe. "I'm not sure I've had a typical workday yet," says Dahl.

Responsibilities vary depending on the time of the semester: "During the beginning of the semester, much of my time is spent developing tutorials, course pages, PowerPoints, and teaching classes. Later in the semester I usually am concentrating on collection development, working with my liaisons in purchasing new books, and weeding," says Tomlinson.

"One day I might work on code for eight hours straight, while another I may teach three info lit classes, update the library's Twitter status, and attend a reference department meeting. The variety of tasks is really endless, and I am lucky enough to work for

\section{Being an ETL doesn't necessarily mean you are a programming computer geek.}

an organization that allows for this sort of variety," says Dahl.

All three of the ETLs are excited about Cook Library's new Text A Librarian service, set to launch in a few weeks. "I think we've just begun to see some of the ways that our knowledge of technology can help the library (and the university as well) to improve our relationship with students, faculty, and staff," says Dahl.

The Text A Librarian project is one in a series of mobile initiatives that include a mobile Web site.

\section{Team work}

Bertling Disclafani, Dahl and Tomlinson consistently collaborate with each other on projects small and large. "We are a team of three recent graduates working within a larger team of librarians with more experience. We all learn from each other," says Bertling Disclafani. With complimenting personalities, their friendship extends beyond the workplace.

"We have the same title, but we have different strengths," says Tomlinson with Bertling Disclafani adding, "I feel like we are much more productive as a team than we could be on our own."

The three coauthor LibraryTechTalk (libtechtalk.wordpress.com), a blog on the use of new technologies in academic librarianship and have presented and facilitated sessions at local and national levels.

So what does being an ETL mean to them? "It means exploration and innovation," says Bertling Disclafani. "Finding, using, teaching, and evaluating new technology to better serve and teach our patrons," says Tomlinson.

"It means being on the cutting edge, being flexible, being creative, solving problems, and bringing others along for the ride. It means never stopping," says Dahl. $\boldsymbol{n}$ 